\title{
WHERE THE RUBBER GLOVE IS BEHIND THE TIMES*
}

\author{
By Robert T. Morkis, M.D., F.A.C.S., NEw York, N. Y.
}

W HEN men smile and agree, progress weeps. At the present moment many men, who would like to express themselves freely on the subject of the rubber glove, are afraid to do so because of complications which might arise in comnection with hospital polities and because of social reactions relating to a convention or established habit in thought. As civilization becomes more and more complex there is a tendency toward standardizations. Standardization represents a natural reaction to radicalism, a necessary reaction to radicalism which, like the rush of antibodies to a point of irritation, may sometimes result in autolysis and destructive end result. The rubber glove belongs to standardization and is onc of its most valuable adjuncts. The standardization idea in every field of human activity represents a great moving force of recognized value. It reaches limitations. A locomotive represents a great moving force. It reaches limitations at the end of a track at a station. If it keeps right on past its limitations it may smash the station. Standardization reaches limitations when it smothers individuality. Some of the labor unions furnish an object lesson. Pictore Darwin standardized to fit the thought of the Established Church of England of his day.

Surgeons, being human, cannot escape human movements and behavior. Whenever we have a high degree of civilization a great deal of painstaking attention is required before men can reach the common level in any sort of professional work. What does this mean in our profession? It means that by the time when all doctors are pretty well agreed upon the desirability of any one resource they are often behind the times. The very best men get behind the times for the reason that their good qualities, recognized by so large a part of the community, have brought them so much vecupation that it has been impossible for them to follow new leaders of thought. They are prone to depend upon tradition. Tradition is the greatest of guides for minds of the mean type and the meanest of guides for minds of the great type. Neurology and psychiatry were beginning to make progress along the lines of objective teaching of Virchow when along came the blight of Freudian mysticism throwing many psychiatrists back to the days of Schelling and Hahnemann in the middle of the last century. Surgenns were getting fairly under way with the principles of the fourth era of surgery when along came the rubber glove acting as a blight upon a rapidly growing subject. Almost all fads have a basis in good fact. The rubber glove had a large basis in good fact, representing one of the most important advances in sur-

* Read at the Thirty-Third Annual Meeting of the American Association of Obstetricians, Gynecologists and Abdominal Surgeons held at Atlantic City, N. J., September 20-22, 1920. 
gery. It reached limitations, ran off the track, and exerted destructive influence upon the fourth era of surgery in its relation to abdominal work. It is in this particular field that the rubber glove is behind the times.

What is the fourth era of surgery? The first era was heroic. Then came the anatomic era. Following the anatomic era, Pasteur and Lister introduced the third or pathologic era. That, was the one in which the surgeon disregarding Nature's resources, attempted to remove bacteria and their products by means of his own resources. He conseientiously acted like the faithful ape that tried to destroy the fly upon his sleeping master's forehead, using a big stone for the purpose. Wright and Metchnikoff then gave us materials which allowed us to construct the basis for a fourth or physiologic era of surgery. That era into which we are just now emerging gives the patient Home Rule. The patient is turned over to himself with the least possible degree of injury to his natural protective resources. He is allowed to manufacture phagocytes and opsonins frecly and this ho does when there has been the least degree of shock to throw the belt from the wheels of his endocrine machinery.

With the introduction of the rubber glove came the longer incision in abdominal surgery. We could see incisions grow in length as rubber gloves became more and more widely adopted. Abdominal surgeons lost their cunning because the sense of touch was interfered with to such an extent that it became necessary for them to do much of their work by the sense of sight, a sense that is recognized as standing second rate to the tactile sense in certain matters of precision. Before the days of rubber gloves there were surgeons, to be sure, who used long incisions and who worked by sight in abdominal surgery, but these were not the ones who had the best results. In that day surgeons, like Lawson Tait and Joseph Price, who worked through small incisions rapidly were the ones who had the best results; Tait, in particular, not only disregarded rules of asepsis and antisepsis but openly railed at them. We could not understand the meaning of the good results of Price and Tait at a time when the colleges were teaching the principles of asepsis and antisepsis. Today we know. The principles of the fourth era of surgery were empirically brought into play by surgeons who worked rapidly through small incisions.

In order to determine the degree to which rubber gloves actually interfered with the tactile sense, I had tests made by an expert upon several physicians and surgeons. The tests all showed a lowering of the tactile sense, even on the part of very expert surgeons and, curiously enough, the physician who stood highest in the tests was not a surgeon but a specialist in the diseases of children.

Dr. T. L. Bennett, the anesthetist, has stated that according to his observation the best surgeon is the one who acts all the while as though he were afraid of waking the patient. Long incisions and thorough examination of viscera wake the patient. Deeper anesthesia becomes neces- 
sary. In natural sequence perhaps to the long incision and working by sight came the later development of thorough examination and exploration of the abdomen with the surgeon's hand introduced through the incision. This in turn had a tendency to lessen the cunning of the diagnostician. It is the forte of the diagnostician to make accurate conclusions in regard to the sites of disturbing factors in advance of operation. When this has been done one or two small incisions frequently allow work to be done more gently and rapidly and more directly to the purpose than is possible through a long comprehensive incision.

No method in surgery is static. We change from one method to another. We have done this in the past and will continue to do so for thousands of years to come. It is my belief that the long incision which belongs to the rubber glove is not static. Surgeons will awaken again to the principles of the fourth era of surgery which, like objective psychiatry, has received a temporary set back.

Does the rubber glove lessen the number of bacteria that are actually carried into an abdominal wound? We may answer that question by way of an object lesson offered by the exposure of culture media in Petri plates in the operating room. The larger the Petri plate the more complete the infection of its contents. The longer the exposure of the Petri plate the more complete the infection of its contents. This infection comes from where? From bacteria falling from the air into the culture medium. More bacteria fall into a large abdominal incision from the air than are carried in by well prepared hands wearing no rubber gloves. We must remember that most of the bacteria which fall into a wound from the air or which are carried in by the hands are destroyed or at least rendered latent by the enzymes of the wound. In addition to the shock caused by the long incision and by thorough examination of viscera, danger from emboli and from postoperative adhesions is greater in degree proportionately to the length of the incision and the lcngth of time expended in opcrating.

Dr. J. W. Kennedy of Philadelphia, states that in a review of one thousand re-operations of the abdomen in his own experience ninety-nine per cent showed adhesions to the scar or in the immediate neighborhood of the scar in patients who had been operated upon previously by men who wore rubber gloves. He states that in his own work only seven per cent of re-operations showed any signs of adhesion to the scar or in its vicinity. Some of the ninety-nine per cent of incision line adhesions were doubtless due to the employment of irritating antisepties for skin preparation of the abdomen. Iodine, for example, valuable as it is, if not removed with alcohol in advance of operation will do to endothelium what it does to epithelium. This fact does not lessen the force of the idea that the longer an incision the more injury to endothelinm.

Rubber gloves have incidentally been a factor in making this a day of instruments in the abdominal cavity. We are prone to forget that the peritoneum with its lymph system is better equipped than is the 
skin for resisting infection. The extent to which the peritoneum will ward off or control infection is remarkable provided that it is not shocked by a blow below the belt. The peritoneum may even wall in material which escapes from a perforated appendix or pylorus or typhoid bowel. Many a surgeon knows this fact but he keeps it walled in. He might have a chill if the fact were suddenly to break through into his thought cavity.

In cases of appendicitis with abscess the plan of making a short incision and of running when pus ran reduced the death rate to such an extent that Dr. L. W. Hotchkiss of New York had a series of seventysix appendicitis operations without a death at a hospital in which the previous death rate in the same class of cases had been thirty-one per cent. In pyosalpinx cases, when working through a short incision after the first acute stages of infection have been brought under control, one may shell out the damaged tubes, split them and fasten them to the anterior abdominal wall and allow the pus to pour out of that exit until the patient responds to vaccine treatment. Six months afterward the abdomen may be reopened, adhesions separated, and the tubes or remains of tubes dropped back into the pelvis, and the patient may then have children. It is true that some of the pregnancies will be extrauterine but the patient, warned of that, is not in great danger because we easily care for an extrauterine pregnancy in its early stages. On the other hand there will be more happy mothers with good babies borne than we find to be possible when a surgeon wearing rubber gloves and working through a long incision commits devastating surgery in the pelvis.

In cases of acute typhoid bowel perforation or gastric ulcer perforation, a two minute operation by a surgeon wearing no gloves will give better service than a thirty-minute operation on the part of a surgeon wearing gloves and working by sight.

Do not mistake the intention of this paper. It does not stand in opposition to the idea of the rubber glove which, in my opinion, represents one of the best advances of the surgery of the day. Personally I use the rubber glove, observing the latest decrees, in practically all of my surgery, with the exception of the peritoneal cavity and when dealing with malignant disease. 'The rubber glove is behind the times when it comes into conflict with the principles of the fourth era of surgery in abdominal work. If conscientious surgeons are behind the times today in their employment of rubber gloves in abdominal work it is not their fault, it is the fault of a public which fails to endow our educational institutions in such a way as to teach young surgeons among other things the difference between the peritoneal cavity and the synovial cavity of the knee joint in regard to their respective responses to injury, mechanical or bacterial. 